\title{
Kritik Hal Çerçevesinde YBCO (358) Süperiletkeninin ZFC İşlemi ile Manyetizasyon-Sıcaklık Değişiminin Modellenmesi
}

\author{
Modelling of the Magnetization-Temperature Change of YBCO (358) Superconductor in \\ Critical State Framework
}

\author{
Meltem AKTAŞ ${ }^{1, \text { a }}$, İshak CUMHUR ${ }^{2, ~ b}$, İbrahim DÜZGÜN*3, c \\ ${ }^{1}$ Milli Eğitim Bakanlığı, Pazar Kız Kulesi Mesleki ve Teknik Anadolu Lisesi, 53300, Rize \\ ${ }^{2}$ Recep Tayyip Erdoğan Üniversitesi, Matematik Bölümü, 53020, Rize \\ ${ }^{3}$ Gümüşhane Üniversitesi, Fizik Mühendisliği Bölümü, 29000, Gümüşhane
}

\begin{abstract}
• Geliş tarihi / Received: 05.06.2020 • • Düzeltilerek geliş tarihi / Received in revised form: 14.07.2020 • Kabul tarihi / Accepted: 17.07.2020
\end{abstract}
\begin{abstract}
$\ddot{\mathbf{O} z}$
$\mathrm{Bu}$ çalışmada, YBCO (358) süperiletkeninin manyetik-moment sıcaklık ölçümleri ve teorik analizleri araştırıldı. Manyetik Moment-Sıcaklık (M-T) eğrilerinin teorik analizi sinterleme sırasında verilen oksijen oranına bağlılı̆̆ olarak yapıldı. Elde edilen deneysel sonuçlarda, oksijen oranının değişiminin Moment-Sıcaklık eğrileri deseninde değişikliğe sebep olduğu görüldü. Deneysel sonuçlar, kritik hal modeli çerçevesinde nitel olarak tartışıldı. Oksijen oranının miktarının artmasıyla $(\% 0,50,100)$, kritik akım yoğunluğunun (Jc) büyüklüğ̈n̈ün sirasıyla 50,100 ve 0 olarak değiştiği bulundu. Her numune için teorik ve deneysel en iyi uyum eğrilerinden kritik akım yoğunluğunun alan ve sıcaklık bağlılığı belirlendi. M-T verilerine göre en iyi uyum eğrileri elde edildi ve kullanılan parametrik değerler her bir numune için karşılaştırıldı. Sonucun literatürle uyumlu olduğu görüldü.
\end{abstract}

Anahtar kelimeler: Kritik Akım Yoğunluğu, Manyetik Moment-Sıcaklık Eğrisi, YBCO (358) Süperiletkenlik

\begin{abstract}
In this study, YBCO (358) superconductor have been investigated by means of magnetic moment-temperature measurements and theoretical analysis. Magnetic moment-temperature curves were evaluated for dependence of oxygen ratio during sintering. From the examinations of the experimental results of the samples, change of oxygen ratio was seen to change the pattern of moment-temperature curves. Experimental results are qualitatively discussed in the framework of the critical state model. The variation of the critical current density values from 50 to 100 and zero, caused the change in oxygen ratio from zero percent to $50 \%$ and $100 \%$, respectively. The field and temperature dependence of the critical current density for each sample were determined from the theoretical and experimental best fit curves. Best fit curves were obtained for M-T data and the used parametric values were compared for each sample. It was seen that the results were consistent with the literature.
\end{abstract}

Keywords: Critical Current Density, Magnetic Moment-Temperature Curve, YBCO (358) Superconductor

\footnotetext{
*a İbrahim DÜZGÜN; ibrahimduzgun@gumushane.edu.tr, Tel: (0506) 61345 23, orcid.org/0000-0002-7319-2619

${ }^{\mathrm{b}}$ orcid.org/0000-0002-2916-0919 ${ }^{\mathrm{c}}$ orcid.org/0000-0001-8550-3835
} 


\section{Giriş}

Charles Palmer Bean tarafindan ortaya konulan kritik hal modeli, yüksek sıcaklık süperiletkenlerin manyetik alanla ilişkisinin analizinde kullanılmaktadır (Bean, 1962). Ortaya koyulan model basit bir mantığa sahiptir. Kritik akım yoğunluğunun $\left(\mathrm{J}_{\mathrm{c}}\right)$, Manyetik ak1 yoğunluğuna (B) bağımlı olmadığı varsayılır. Buna rağmen, Young Bae Kim ve arkadaşları mevcut modeli kritik akım yoğunluğunun manyetik akı yoğunluğuna bağlı olarak yeniden düzenledi (Kim vd., 1963). Ayrıca bazı araştırmacılar bir üs yasası modeli önerdiler (Irie vd., 1967; Green vd., 1967). Üs yasasına göre kritik akım yoğunluğu manyetik akı yoğunluğuna pozitif bir sabit olan " $n$ " gibi bir kuvvet ile bağlıydı. $\mathrm{Bu}$ modeller alt kritik alan $\mathrm{H}_{\mathrm{cl}}$ 'in altındaki akı dışarlama etkisini göz ardı ettiler. 1964 yılına gelindiğinde kritik hal modelini denge manyetizasyonu ile iyileştiren bir üstel model rapor edildi (Fietz vd.,1964). John Richard Clem, malzemenin içine akı girişi $\left(\Delta \mathrm{H}_{\mathrm{en}}\right) /$ çıkışı $\left(\Delta \mathrm{H}_{\mathrm{ex}}\right)$ için fazladan alan artışı gerektiren yüzeyde potansiyel bariyeri içeren bir kritik hal modeli ileri sürdü (Clem, 1979). Şimdiye kadar öne sürülen farklı kritik hal modellerinin bir özeti için verilen referanslara bakılabilir (İnanır, 2006; Aktaş, 2019).

Yüksek sıcaklık süperiletkenlerinde kritik akım yoğunluğunun sıfır olduğu ve manyetik davranışın diyamanyetik olduğu bir bölgenin varlığ bilinmektedir. $\mathrm{Bu}$ bölge manyetik alan-sıcaklık
(H-T) faz diyagramında tersinmezlik çizgisi (irreversibility line) sayesinde belirlenir ve bu çizgi tersinir ve tersinmez bölgeyi ayırıcı olarak tanımlanır. Tersinmezlik çizgisinin üzerindeki bölgede süperiletken malzemenin manyetizasyonu tamamen tersinir altındaki bölgede ise manyetizasyonun davranışı histeriktir. Fiziki açıdan anlamı ise çivilenme kuvvetinin akı çizgilerinin üzerinden kaldırıldığı alana karşılık gelmesidir (Seeber, 1998). İlk olarak tersinmezlik çizgisi üzerine araştırma raporunu Müller ve arkadaşları tarafından yayınlandığı görülmektedir (Müller vd., 1987). Tersinmezlik çizgisinin bulunuşuna dair ayrıntılı metotlar için Düzgün ve arkadaşlarının çalışması güzel bir kaynak oluşturmaktadır (Düzgün vd., 2010).

$\mathrm{Bu}$ çalışmada, katıhal tepkime yöntemi ile üretilen YBCO (358) süperiletkeninin Manyetik Moment Sıcaklık ölçümleri ve teorik analizleri araştırıldı.

\section{Gereç ve Yöntem}

\subsection{Süperiletken Numunelerin Hazırlanmast}

$\mathrm{Bu}$ çalışmada kullanılan numunelerin hazırlanması yapısal özellikleri ve manyetik ölçümleri (Başoğlu vd., 2016) 'da ayrıca yapının örgü parametreleri (Düzgün, 2018)'de ayrıntılı bir şekilde verilmektedir. Seçilen başlangıç kompozisyonunun hazırlanmasında aşağıdaki eşitlik kullanılmıştır.

$$
(0.5)\left(\mathrm{Y}_{2} \mathrm{O}_{3}\right)+(5)\left(\mathrm{BaCO}_{3}\right)+(8)(\mathrm{CuO}) \rightarrow \mathrm{Y}_{3} \mathrm{Ba}_{5} \mathrm{Cu}_{8} \mathrm{O}_{18+\delta}+(5)\left(\mathrm{CO}_{2}\right)
$$

Numuneler $840^{\circ} \mathrm{C}^{\prime}$ de 24 saat kalsine edildi. Kalsinasyon işleminden sonra numuneler 5 saat içerisinde oda sicaklığına soğutuldu. Numuneler daha sonra $930^{\circ} \mathrm{C}$ 'de 24 saat boyunca uygun oksijen ve argon gazı ortaminda sinterlendi. Sinterleme sonrasında elde edilen toz karışımı 12 mm çapında ve $1 \mathrm{~mm}$ kalınlığında olmak üzere $\sim 220$ bar basınç altında pellet haline getirildi. Numuneler, $950^{\circ} \mathrm{C}^{\prime}$ ye oksijen ortamında 24 saat tavland. $\mathrm{Bu}$ sürenin bitiminde tabletler $500^{\circ} \mathrm{C}$ 'ye kadar soğumaya birakıldı. Numuneler N0, N50 ve N100 olarak isimlendirildi. Burada 0, 50 ve 100 oksijen oranını belirtmektedir.

\subsection{Süperiletken Numunelerin Manyetik Özelliklerinin Ölçümü}

Manyetik ölçümler, Quantum Design PPMS sistemi kullanılarak yapılmıştır. Numunelerin uzunluğu manyetik alana paralel olacak şekilde monte edilmiştir. Numunenin boyutları $2.5 \times 2.5 \times 1.5 \mathrm{~mm}^{3}$ olarak ölçüldü. Ölçüm sistemi, uygulanan manyetik alana göre moment değişimini verecek şekilde kapalı devre soğutma sistemi $4-330 \mathrm{~K}$ arasında sicaklık kontrolü sağlayabilen kompakt bir sistemdir. Ayrıca manyetik alınganlığın gerçek ve imajiner kısımlarını; sicaklığın, uygulanan $\mathrm{AC}$ alan genliğinin ve frekansının fonksiyonu olarak ölçebilecek şekilde dizayn edilmiştir. Tüm süperiletken malzemeler için Manyetik momentSicaklık verileri $20-120 \mathrm{~K}$ arasında $\mathrm{H}=250 \mathrm{Oe}$ sabit alan ve manyetik alan numunenin c eksenine paralel olacak şekilde ölçülerek elde edilmiştir. 


\section{Bulgular ve Tartışma}

Bean ve basit Kim modellerinde Meissner katkısı göz ardı edilmektedir. Yani $\mathrm{H}_{\mathrm{cl}}=0$ kabulü yapılır. Ayrıca, Bean modeline göre $J_{c}$ kritik akım yoğunluğu manyetik alandan bağımsız kabul edilmektedir. Kim modelinde kritik akım yoğunluğu manyetik alan ile $\mathrm{H}^{-1}$ orantısına sahiptir. Daha reel bir model için hem Meissner akımını hem de $J_{c}$ 'nin alan bağımlılı̆̆ını içermesi gerekir. Teorik hesaplamalar Mathematica programından yararlanılarak yapılmıştır. Hem silindir hem de dilim (slab) geometrisi için manyetizasyon ölçümlerinin teorik hesaplamaları (Öztürk, 2005) doktora tezinde ayrıntılı olarak yapılmıştır. $\mathrm{Bu}$ çalışmada benzer denklemler yardımıyla, sıfır alanda soğutma (ZFC) işlemine göre Miknatıslık-Sicaklık verilerine en iyi uyumu verecek biçimde, denklemler türetilmiş ve üretilen malzeme için bazı süperiletkenlik parametreleri teorik olarak hesaplanmıştır. Dilim geometrisi için denklemler aşağıda verilmiştir.

Kritik akım yoğunluğunun manyetik alan ve çivileme bağımlılığ için

$$
I_{c}(H, T)=\frac{I_{c o}(T)}{\left[\frac{H_{a}+H_{0}-I_{M}}{H_{\text {reff }}}\right]}
$$

denklemiyle belirlenen fonksiyon biçimindedir. Eşitlikte yer alan $\mathrm{H}_{\mathrm{a}}$ uygulanan manyetik alanı, $\mathrm{H}_{0}$ bir sabit, $\mathrm{I}_{\mathrm{M}}$ ise alan bağımlı Meissner akımını ifade etmektedir. $\mathrm{H}_{\mathrm{ref}}$ ise $\mathrm{J}_{\mathrm{c} 0}(\mathrm{~T})$ teriminin akım yoğunluğu biriminde olduğunu garantilemek için verilmektedir. Meissner akımı iki pozisyonda olabilir. İlk olarak $\mathrm{H}_{\mathrm{a}} \leq \mathrm{H}_{\mathrm{cl}}$ durumunda $\mathrm{I}_{\mathrm{M}}=\mathrm{H}_{\mathrm{a}}$ olacaktır. Diğer durum için ise $\left(\mathrm{H}_{\mathrm{a}} \geq \mathrm{H}_{\mathrm{cl}}\right)$;

$I_{M}=\frac{H_{C 1}}{\left[\frac{H_{a}}{H_{c 1}}\right]^{p}}=\frac{H_{c 1}^{p+1}}{H_{a}^{p}}$

şeklinde p üsteli ile belirlenebileceği gösterilmiştir. Sonsuz uzunlukta ve genişlikte $2 \mathrm{X}$ kalınlığa sahip dilim geometrisine sahip süperiletken malzeme için,

$\vec{\nabla} x \vec{H}=\vec{J}_{\epsilon}$

Maxwell denklemi (Ampère Yasası) kullanılarak,

$\mathrm{J}_{\mathrm{c}}=\frac{\mathrm{dH}}{\mathrm{dx}}$

elde edilir. $\mathrm{Bu}$ kısımda ak1 yoğunluğu konfigürasyonuna ait $\mathrm{H}(\mathrm{x})$ denkleminin bulunabilmesi için profile ait olan eğrinin sinırlarından faydalanılır. Kolaylık açısından 0 noktasına göre simetrik olan malzemenin $0-\mathrm{X}$ kısmı üzerinde durulur. Dilim geometrisi için,

$\mathrm{H}(\mathrm{x})=\left[\left(\mathrm{H}_{\mathrm{a}}+\mathrm{H}_{0}-\mathrm{I}_{\mathrm{M}}\right)^{\mathrm{n}+1}-\alpha(1+\mathrm{n})(\mathrm{x}-\mathrm{x})\right]^{\frac{1}{\mathrm{n}+1}}-\mathrm{H}_{0}$

eşitliği elde edilir. Dilim geometrisine sahip malzemeler için manyetizasyon hesaplamalarında

$<M>=\frac{1}{\mathrm{X}} \int \mathrm{H}(\mathrm{x}) \mathrm{dx}-\mathrm{H}_{\mathrm{a}}$

integrali çözülmelidir. (6) eşitliğindeki $\mathrm{H}(\mathrm{x})$ ifadesi, integralin sinırları malzemeye uygulanan manyetik alanın arttırılması ve azaltılmasıyla akı yoğunluğu konfigürasyonun alacağı duruma göre belirlenmelidir.

Bu çalışmada ele alınan M-T (Manyetik MomentSicaklık) grafiklerini fiziksel olarak fit edecek denklemler, Maxwell denklemlerinden türetilen yukarıdaki eşitlikler kullanılarak elde edilmiştir.

$\gamma=\gamma p * f * \mathrm{~T}_{\mathrm{irr}}^{2}$

$\mathrm{H}_{\mathrm{a}}=\frac{1}{\gamma}\left(1-\mathrm{t}_{\mathrm{c} 1}^{2}\right)$

$\mathrm{I}_{c}(\mathrm{~T})=\left(1-\frac{\mathrm{t}^{\mathrm{a}}}{\mathrm{T}_{\mathrm{irr}}^{\mathrm{g}}}\right)^{\mathrm{k}}$

$I_{M}=\frac{1}{\gamma} \frac{\left(1-t^{2}\right)^{p+1}}{\left(1-t_{C 1}^{2}\right)^{p}}$

$H(x)=\left[\left(\frac{1}{\gamma}\left(1-t_{c 1}^{2}\right)-I_{M}\right)^{n+1}-J_{c}(T)(1-x)\right]^{\frac{1}{n+1}}$

Bu eşitliklerde $\gamma, f, \gamma p, T_{\text {irr }}, k, p$ ve $n$ sabittir. $T_{\text {irr }}$ parametresi, alan altında soğutma (FC) ve ZFC süreçlerinin ayrıldığı noktadaki sıcaklık değeridir. Diğer adıyla tersinmezlik sıcaklığıdır. $\mathrm{x}$ numuneye ait kalınlığ vermekte olup manyetik alanın girme derinliğiyle yakından ilişkili bir parametredir. Program çalıştırılırken sıcaklık ekseni en yüksek sıcaklık değerine bölünerek normalize edilmiş̧ir. Yukarıda bahsi geçen parametreler bu normalize olmuş değerlere göre seçilmiştir. 


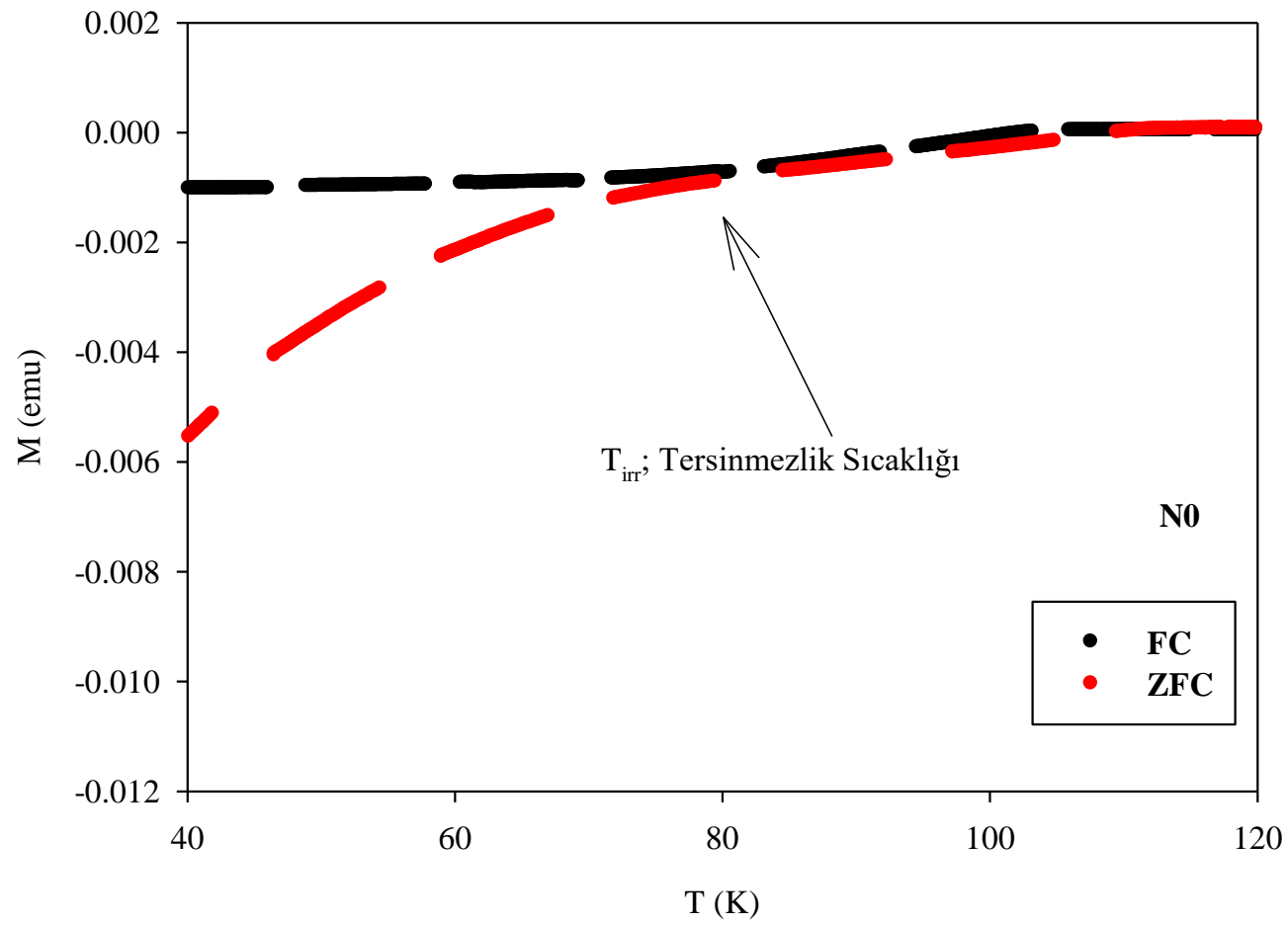

Şekil 1. N0 süperiletken numunesine ait FC ve ZFC deneysel eğrilerinin grafiği ve Tersinmezlik sicaklığının $\left(T_{\text {irr }}\right)$ gösterimi

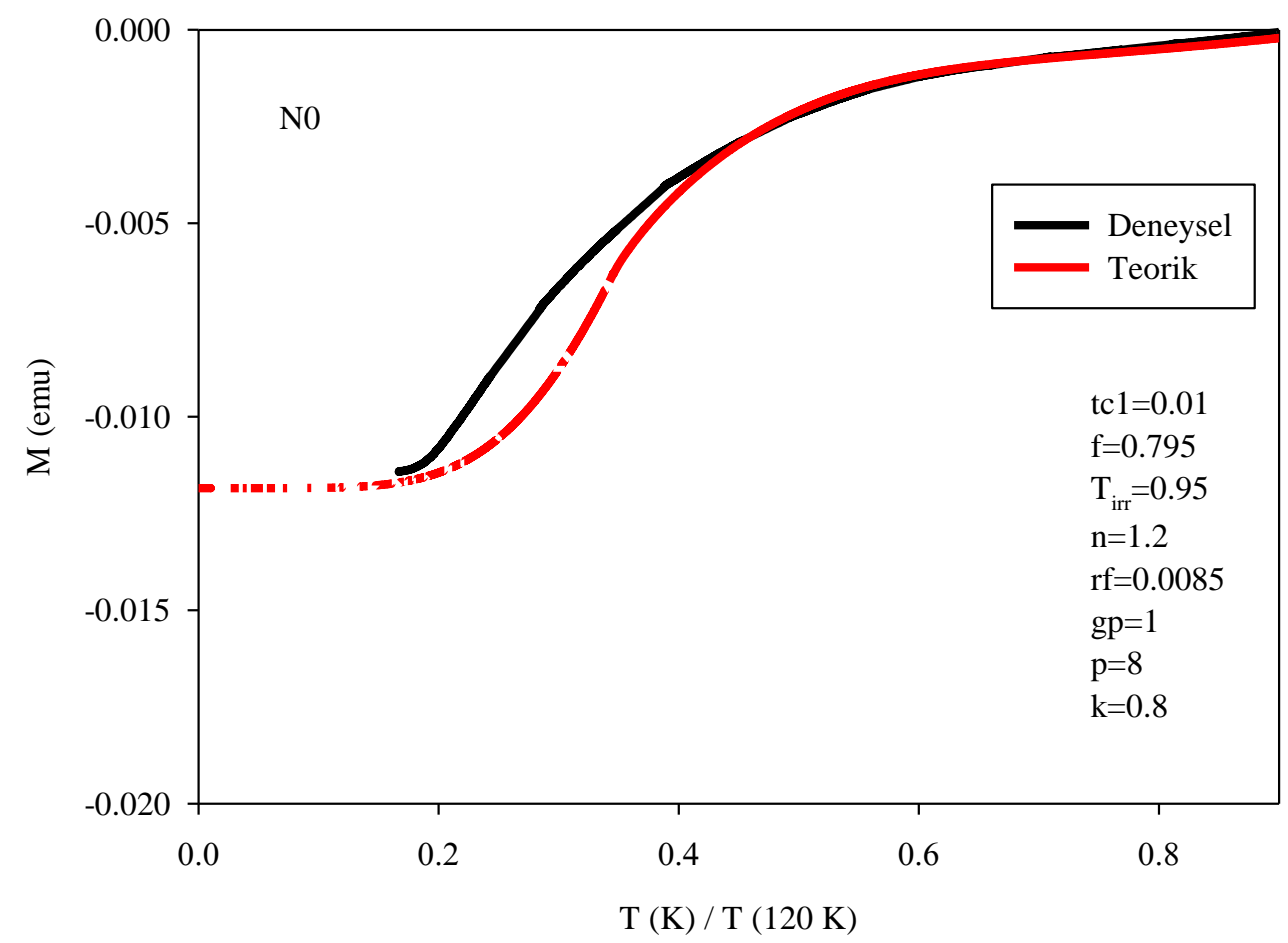

Şekil 2. N0 süperiletken numunesine ait deneysel ZFC eğrisi ve teorik fit eğrisi. 


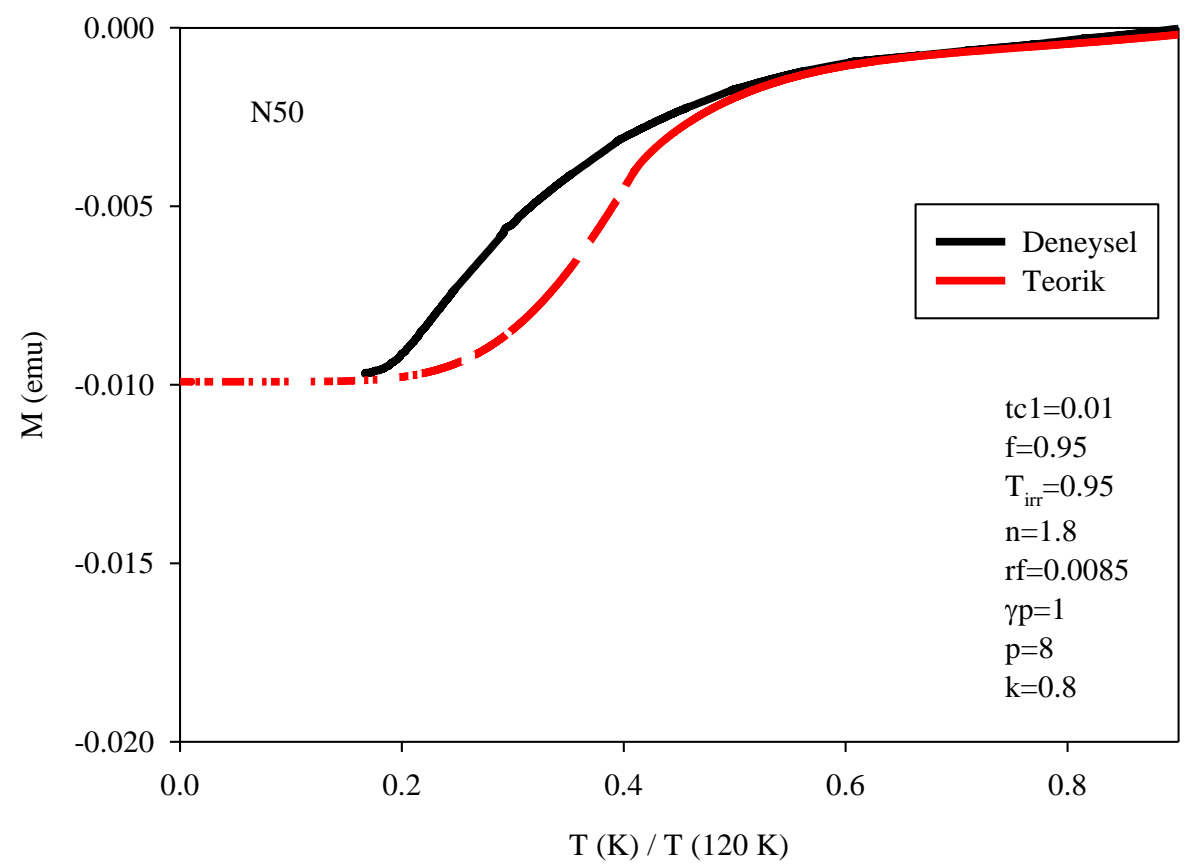

Şekil 3. N50 süperiletken numunesine ait deneysel ZFC eğrisi ve teorik fit eğrisi.

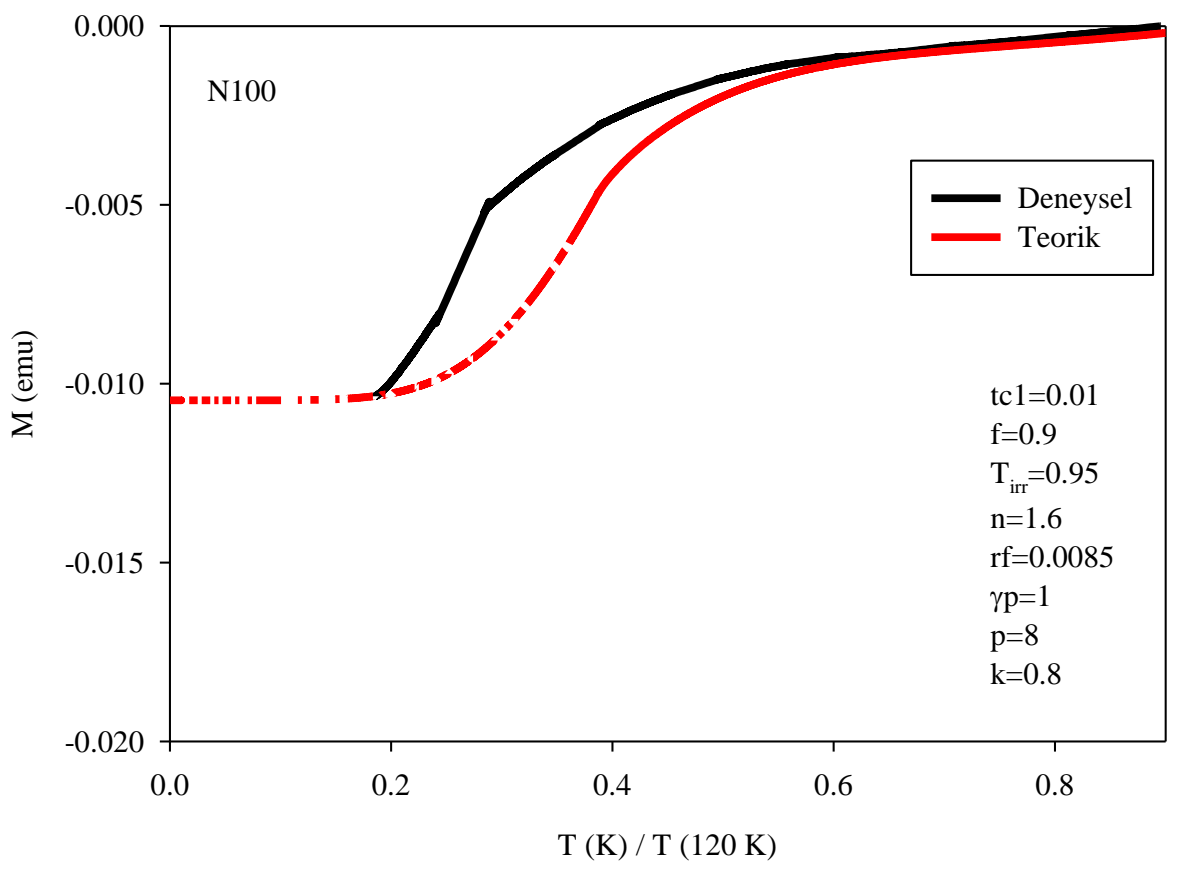

Şekil 4. N100 süperiletken numunesine ait deneysel ZFC eğrisi ve teorik fit eğrisi.

Şekil 2,3 ve 4'de gösterildiği üzere $T_{\text {irr }}$ parametresi üç süperiletken malzeme için belirlenmiştir. Daha sonra fiziksel değeri olan verilerin mathematica programı yardımıyla teorik olarak deneysel verilere en iyi uyum sağlayacak şekilde yeniden türetilmesi sağlandı. Tablo 1'de kullanılan parametreler ve değerler her bir numune için gösterildi.

Tablo 1. Üç numune için teorik olarak elde edilen parametrik değerler

\begin{tabular}{|c|c|c|c|c|c|c|c|c|}
\hline & $\mathbf{n}$ & $\mathbf{f}$ & $\mathbf{t}_{\mathbf{c l}}$ & $\mathbf{T}_{\text {irr }}$ & $\mathbf{r f}$ & $\gamma \mathbf{p}$ & $\mathbf{p}$ & $\mathbf{k}$ \\
\hline $\mathbf{N 0}$ & 1.2 & 0.795 & 0.01 & 0.95 & 0,0085 & 1 & 8 & 0.8 \\
\hline N50 & 1.8 & 0.950 & 0.01 & 0.95 & 0.0085 & 1 & 8 & 0.8 \\
\hline N100 & 1.6 & 0.900 & 0.01 & 0.95 & 0.0085 & 1 & 8 & 0.8 \\
\hline
\end{tabular}


Burada $\mathrm{n}$ parametresi kritik akım yoğunluğunun manyetik alana bağlılığını gösteren parametredir. f parametresi numuneler için elde edilen $\mathrm{T}_{\text {irr }}$ değerinden sonra grafiğin geri kalan kısmını fit edebilmek için gerekli olan katsayıdır. Geri kalan parametreler her üç numune için de aynı değere sahip olup değişimin sadece $\mathrm{n}$ parametresine ait olduğu görülmektedir. 2016 yılında Başoğlu ve diğerleri tarafindan (Başoğlu, 2016) yayınlanan çalışmada, Y358 numunesine ait kritik akım yoğunluğunun karşılaştırılması yapılmış büyükten küçüğe doğru sirasiyla N50, N100 ve N0 numunelerine ait olduğunu hem deneysel hem de M-H ölçümlerinden göstermişlerdir.

Burada elde edilen sonuçta literatürü doğrulamakta olup en iyi uyum eğrilerinin elde edildiğini göstermektedir.

\section{Sonuç}

$\mathrm{Bu}$ çalışmada, üç farklı YBCO (358) yüksek sicaklık süperiletkenin manyetik moment- sicaklik özellikleri kritik hal modeli hesapları ile araştırıldı.

Sabit alanda (250 Oe) ölçülen moment- sıcaklık verilerinden, sinterleme ortamında verilen oksijen oranına göre kritik akım yoğunluğunun literatür ile uyumlu şekilde olduğu gözlendi.

Modellemede kullanılan kritik hal modeli (Bean ve basit Kim modeli) yardımıyla türetilen denklemler M-T verilerinden elde edilen ZFC eğrisine oldukça iyi derecede uyum sağladığı görüldü.

Modellemede kullanılan ve açıklamaları makalede anlatılan $\mathrm{n}, \mathrm{T}_{\mathrm{irr}}, \mathrm{p}$ gibi bazı süperiletkenlik parametreleri elde edildi.

\section{Kaynaklar}

Aktaş, M., 2019. YBCO (358) Süperiletkenlerinin Mıknatıslanma-Sıcaklık Değişiminin Kritik Hal çerçevesinde Modellenmesi, Yüksek Lisans Tezi, Recep Tayyip Erdoğan Üniversitesi Fen Bilimleri Enstitüsü. Rize, 42s.

Başoğlu, M., Düzgün, İ., 2016. Improvement of Current Density of Different AtmosphereSintered Y358 Superconductors. Journal of Superconductivity and Novel Magnetism, 29, 1737- 1740.

Bean, C.P., 1962. Magnetization of Hard Superconductors. Physical Review Letters, 8, $250-253$.
Bean, C.P., 1964. Magnetization of High-Field Superconductors. Review of Modern Physics, $36,31-38$.

Clem J. R., 1979. Theory of AC Losses in Type-II Superconductors with A Field-Dependent Surface Barrier. Journal of Applied Physics., 50, 3518.

Düzgün, İ., Öztürk, A., Çelebi, S., 2010. Irreversibility Line and Flux Relaxation in Bi:2223/Ag Tape Prepared by CTFF Technique: H//c Axis. Journal of Superconductivity and Novel Magnetism, 23, 1349-1354.

Düzgün, İ., 2018. The Investigation of the Lattice Strains and Crystallite Sizes of Y358 and Y123 High-Temperature Superconductors. Turkish Journal of Physics, 42, 378-385.

Fietz, W. A., Silcox, J., Beasley, M. R., Webb, W.W., 1964. Magnetization of Superconducting Nb25\%Zr Wire. Physical Review A, 136, 335-345.

Green, I. M., Hlawiczka, P., 1967. Pinning Forces and Hysteresis in Type 2 Superconductors, Proceedings of The Institution of Electrical Engineers, 114, 1329.

Irie, F., Yamafuji, K., 1967. Theory of Flux Motion in Non-Ideal Type-II Superconductors. Journal of the Physical Society of Japan, 23, 255-268.

İnanır, F., 2006. Farklı Alan Etkileri İçin II. Tip Süperiletkenlerin Manyetikzorlamının Modellenmesi, Doktora Tezi, Karadeniz Teknik Üniversitesi Fen Bilimleri Enstitüsü, Trabzon, $141 \mathrm{~s}$.

Kim, Y.B., Hempstead, C.F., Strnad, A.R., 1962. Critical Persistent Current in Hard Superconductors. Physical Review Letters, 9, 306-309.

Kim, Y.B., Hempstead, C.F., Strnad, A.R., 1963. Magnetization and Critical Supercurrents. Physical Review, 129, 528-534.

Müller, K.A., Tagashie M., Bednortz, J.G., 1987. Flux Trapping And Superconductive Glass State In La2CuO4-y:B. Physical Review Letters, 58, 1143.

Öztürk, A., 2005. Yüksek Sicaklık Süperiletkenlerinin Elektriksel ve Manyetik Özelliklerinin Deneysel ve Modelleme ile İncelenmesi, Doktora Tezi, Karadeniz Teknik Üniversitesi Fen Bilimleri Enstitüsü, Trabzon, 146s.

Seeber, B., 1998. Handbook of Applied Superconductivity 1. Cilt: Bristol, Institute of Physics Publishing, 1139s. 